\section{Psychotic Disorder Due to Lafora Disease: A Case Report}

\section{Şafak Taktak ${ }^{1}$, Mustafa Karakuş²}

\author{
1 Psychiatry Department, Ahi Evran \\ University Education and Research \\ Hospital, Turkey \\ 2 Forensic Medicine and Emergency \\ Medicine Department, Yenimahalle \\ Education and Research Hospital, Turkey
}

\begin{abstract}
Lafora disease is a type of progressive myoclonic epilepsy with poor prognosis, characterized by myoclonus, seizures, cerebellar ataxia and mental disorder. Lafora disease frequently develops at 10-18 years of age and tranmission is autosomal recessive. The first symptoms are usually myoclonic, tonic-clonic, atonic or absence seizures. Epilepsy in children and adolescents with depression, anxiety disorders, attention deficit hyperactivity disorder can be seen relatively frequently. More rarely, these people can be seen in psychotic disorders. In this paper, we aimed to draw attention to diagnosis of fatal, resistance to treatment with serious suicide attempt and diagnosis of Lafora developing psychotic symptoms in children.
\end{abstract}

\section{Corresponding author: Şafak Taktak}

Psychiatry Department, Ahi Evran University Education and Research Hospital, Turkey

\section{Đdrstaktak@hotmail.com}

Tel: 05054037967

\section{Introduction}

Epilepsy in childhood, with prevalence 0,5-1\%, are among the most common neurological diagnosis. Progressive myoclonic constitutes less than $1 \%$ of all epilepsies, while Lafora disease constitutes $10 \%$ of all epilepsies. Lafora disease is a type of progressive myoclonic epilepsy with poor prognosis, characterized by myoclonus, seizures, cerebellar ataxia and mental disorder. Lafora disease is rare, frequently develops at $10-18$ years of age, tranmission is autosomal recessive. Lots of research has shown that the incidence of psychopathology in children and adolescents diagnosed with epilepsy between 21-60\%. Epilepsy may be associated with cognitive and behavioral changes so it is associated with significant psychiatric illness. The underlying neurological dysfunction in these patients can result in increased susceptibility to psychiatric disorders. As well as chronic nature of the disease associated with epilepsy that psychosocial factors may also play a role in the emergence of psychiatric corrupt. Although with regard to the diagnostic methods and different sample sizes used, the frequency of psychiatric disorders varies between studies, mood disorders (24-74\%), especially depression $(30 \%)$ are reported as the most common comorbidity. These rates are followed by anxiety disorders with $10-25 \%$, psychosis with $2-7 \%$ and personality disorders with $1-2 \%$. Psychotic symptoms in childhood epilepsy are observed less frequently. Epileptic seizures cause confusion in diagnosis and treatment because seizures can occur with psychiatric symptoms clinically. In this paper, Lafora disease that 4 years ago began an epileptic seizure, since the beginning of neurological and psychiatric examinations and treatments that have been made but not seen any benefit from effective treatment and resulting in death was reported, as a case report [1-11].

\section{Case}

The index case, a 12-year-old girl, who had a family history of schizophrenia (in father) and epilepsy (in mother \& grandmother) presented in this paper is a rare case in which the child died in four years. Besides its being rare, without any specific disorders in cognitive functions, it is a mental disorder case while it has been identified in the literatüre that there is a progressive cognitive decline in Lafora. This girl in the seventh grade, after returning from school, slept in her room and then could not be awakened in the morning, which then uriner incontinence was recognized and she was taken to hospital. She was awakened 3 days later and EEG in the upper brain stem and primary generalized epileptiform from midline structures determined that an abnormality. Immediately after the attacks on the drive. Despite the fact that he increasing doses of valproic acid $3000 \mathrm{mg} /$ day, carbamazepine $800 \mathrm{mg} /$ day have been used, it was not associated with an improvement in the disease. The first three years passed at least three times a week, asleep in the arms and legs as jerking described by mother seizures have been learned over the last year through every day. After the first attack irritability, suspiciousness, hiper-mobility, inobedience to, patient with aggression attempted suicide by drinking a year after their heart medications at home. Followed by psychiatrists, sertraline $50 \mathrm{mg} / \mathrm{day}$ and risperidone $2 \mathrm{mg} /$ day was started, it was found that no improvement and at least three times a week in the emergency department were made Diazepam $10 \mathrm{mg}$ IM. It was found the 
last three years in a psychiatric ward 9 times briefly at admission was made. It was also found that routine biochemistry, complete blood count, thyroid hormones, and the vitamin levels were within normal limits. When psychiatry files examined, generally being willing to communicate, psychomotor activity from time to time increased, which is properly association, affects the variable it is, sexual content and paranoid delusions of thought content, auditory and visual hallucinations, orientation, being sufficient attention and memory was found. Although in the treatment of patient, amisulpride, trifluperazine, quetiapine, chlorpromazine, haloperidol, risperidon were used, constantly running away from home, the exit in front of the speeding car, went to the police station constantly complained by saying "my family killed me at home, the family raped me" has been determined. As a precaution, the patient was placed in the girls dorm. This patient was found to jump from the third floor of the dormitory. It is also found that walking does not interfere with the first and second lumbar vertebrae in the upper plateau destruction and the loss of light height. This girl is jumping in front of cars going fast once a week. MRI has been identified as the patient in the EEG, cerebral bioelectrical in hemispheric back half activity, age is not consistent with minimal ground rhythm disorder. MRI did not reveal any pathology in the brain a year before she died. Hepatomegaly and splenomegaly was found in the upper abdomen ultrasonography. Made in genetic analysis; EPM2 the gene was determined that the deletion. Also, mutation was not found in the indicated exon scanned. The diagnosis was Lafora and Clobazam $30 \mathrm{mg} /$ day was added to treatment but, it was indicated that these drugs do reduce irritability outside of a clinical correction. Background activity of the patient's death a month ago in the captured video encephalography right hemisphere is slower in the region sentroparietal significant seizure activity was not observed during clinical observations were reported. It is identified improper ground rhythm disorder with the patient's age through the video EEG monitoring. The patient, reached from 45 kilos to 110 kilos in four years, has attempted suicide many times. Because of recognizing uriner incontinence, is connected to cloth under the patient. Double vision problems in patient file was seen Lees Screen test done but the results of the test are expressed not reached. Especially over the last year in order to reduce psychotic relapse in emergency service at least once a week, haloperidol has to be done $10 \mathrm{mg}$ of haloperidol and biperiden $5 \mathrm{mg} I \mathrm{IM}$. She died at the age of 16 , had not awakened when she last seizure, due to come foaming at the mouth and bruising was admitted to intensive care. Two days later it was learned that the patient died with pneumonia aspiration.

\section{Discussion}

Epilepsy comorbid psychiatric disorders may begin before epilepsy, or epilepsy may occur simultaneously available after. In our case, the disorders began after the seizure. Despite the use of a variety of antiepileptics, it is not seen that cutting of epileptic seizures. Besides, seizures passed through at least three times a week, while last year it is observed that passed seizures every day. Psychotic symptoms are sorted by time occurrence associated with seizures. Only the psychotic symptoms during seizures are called as "ictal psychoses", whereas psychotic symptoms shortly after emerging are called as "post-ictal psychosis". In postictal psychoses, psychotic symptoms and emotion symptoms are short perioded ( $24 \mathrm{hr}$ to 3 months) while in his case the period is almost 4 years and everyday during all this time. On the other hand, in post-ictal psychoses mostly no attacks are observed whereas in this case attacks almost never stop and psychopathology continuously exists. As for resulting in seizures, persistent psychotic symptoms of schizophrenia-like is called as "interictal psychosis". In some epileptic patients, especially generally within $24 \mathrm{hr}$ following the seizure disorder at different levels of consciousness, hallucinations and suicide attempts can be monitored relation to aggression, eksiyasyo's paranoid delusions and hearing contained in. Symptoms of our cases are similar both post-ictal seizures and interictal seizure. Epileptic psychosis, can be clinically observed in the absence of seizures, schizophrenia can be thought, due to the presence of positive symptoms such as delusions and hallucinations. Childhoodonset schizophrenia cases are less responsive to treatment. Also, they possess less favorable prognosis. In these cases, the period before the disease as well as social and behavioral problems, learning difficulties can be found. Before any seizure disorder was not detected in our case. Academic life of our patient after the seizure is over. In this case the because of lack of insight into the patient's psychotic symptoms, functionality of corruption, and the presence of the father in schizophrenia, she could not be ignored in schizophrenia. Altought during the first year since the onset of seizures it was only given antiepileptics, both seizures can not be prevented, and the patients with mental disorders has increased. Besides, the patient began psychiatric treatment after a suicide attempt. It is identified that antiepileptic drugs, antipsychotics, antidepressants made patients calmed only for short periods but did not cure, same frequency continuing epileptic seizures, the patient's weight was more than doubled in 4 years, the patient no longer started walking and visual impairment, the patient's mother started using antidepressants, his father increased the antipsychotic dose. As a result, we believe that new research for fatal 4 years and very rare Lafora, and also Lafora patients, especially psychotic disorders, needs to be done to treat [12-19]. 


\section{References}

1 Shackleton DP1, Westendorp RG, Kasteleijn-Nolst Trenité DG, de Boer A, Herings RM (1997) [Dispensing epilepsy medication: a method of determining the frequency of symptomatic individuals with seizures]. J Clin Epidemiol 50:1061-1068.

2 Güler A, Gökçay A, Kandiloğlu G, Özbay OE (2009) [Lafora disease presented with juvenile myoclonic epilepsy clinical features]. Ege Journal of Medicine 48 : 131-134.

3 Ozalp E, Fevziye T (2013) [Psychiatric Disorders in Children and Adolescents with Epilepsy]. Current Approaches in Psychiatry 5:60-77.

4 Cankurtaran ES, Ulug B, Saygı S (2004) Comorbid psychiatric disorders in epilepsy. Bulletin of Clinical Psychopharmacology 14: 97-106.

5 Unver O, Demirkesen C, Uysal S (2011) Lafora disease: a progressive myoclonic epilepsy. Turk Arch Ped 46: 161-163.

6 Torta R, Keller R (1999) Behavioral, psychotic and anxiety disorders in epilepsy:etiology, clinical features, and therapeutic implications Epilepsia 40: 2-20.

7 Kwan P, Brodie MJ (2001) Neuropsychological effect of epilepsy and antiepileptic drugs. Lancet 357:216-222.

8 Kanner AM, Dunn DW (2004) Diagnosis and management of depression and psychosis in children and adolescent with epilepsy. J Child Neurol 19: 65-72.

9 Gaitatzis A, Trimble MR, Sander JW (2004) Psychiatric comorbidity of epilepsy. Acta Neurol Scand 110:207-220.
10 Swinkels WA1, Kuyk J, van Dyck R, Spinhoven P (2005) Psychiatric comorbidity in epilepsy. Epilepsy Behav7: 37-50.

11 Güney E, Uneri ÖŞ, Arhan EP, Karalok ZS (2014) A case report of ictal psychosis diagnosed in childhood period. Anatolian Journal of Psychiatry 15:31-34.

12 Lipton RB, Silberstein SD (1994) Why study the comorbidity of migraine? Neurology 44: 4-5.

13 Sachdev P (1998) Schizophrenia-like psychosis and epilepsy: The status of the association. Am J Psychiatry 155: 325-336.

14 Güney E, Hirfanoğlu T, Serdaroğlu A, Sener S, Iseri E (2008) Epileptik Psikoz: Bir Olgu Sunumu. Klinik Psikiyatri 11:95-100.

15 Cankurtaran ES, Ulug B, Saygı S (2004) Comorbid psychiatric disorders in epilepsy. Bull Clin Psychopharmacol 14:97-106.

16 Kayatekin EZ (1998) Epilepsi ve Psikoz. Düşünen Adam 2:115-123.

17 Işık E b(1999) Nevrozlar, Organik Psikiyatri, Kent Matbaası, Ankara 305-317.

18 Adachi N1, Hara T, Oana Y, Matsuura M, Okubo Y, et al. (2008) Difference in age of onset of psychosis between epilepsy and schizophrenia. Epilepsy Res 78:201-206.

19 Yüksel T, Cumurcu BE, Ozcan OO (2013) Differential diagnosis of childhood onset psychotic symptoms. Journal of Mood Disorders 3:86-89. 